\title{
Article
}

\section{Theorizing healthy settings: a critical discussion with reference to Healthy Universities}

Dooris, Mark T, Wills, J and Newton, J

Available at http://clok.uclan.ac.uk/11491/

Dooris, Mark T ORCID: 0000-0002-5986-1660, Wills, J and Newton, J (2014)

Theorizing healthy settings: a critical discussion with reference to Healthy Universities. Scandinavian Journal of Public Health, 42 (15 Sup). pp. 7-16. ISSN $1403-4948$

It is advisable to refer to the publisher's version if you intend to cite from the work. http://dx.doi.org/10.1177/1403494814544495

For more information about UCLan's research in this area go to http://www.uclan.ac.uk/researchgroups/ and search for <name of research Group>.

For information about Research generally at UCLan please go to http://www.uclan.ac.uk/research/

All outputs in CLoK are protected by Intellectual Property Rights law, including Copyright law. Copyright, IPR and Moral Rights for the works on this site are retained by the individual authors and/or other copyright owners. Terms and conditions for use of this material are defined in the policies page.

\section{CLoK}

Central Lancashire online Knowledge www.clok.uclan.ac.uk

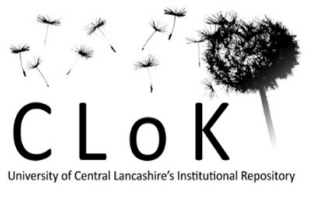




\section{Theorising Healthy Settings: a critical discussion with reference to Healthy Universities}

Mark Dooris, Director of Healthy Settings Development Unit / Professor in Health and

Sustainability

University of Central Lancashire, Preston UK

email: mtdooris@uclan.ac.uk

Telephone: 01772893760

Jane Wills, Professor of Health Promotion, London South Bank University, London, UK

Joanne Newton, PhD Student, London South Bank University, London, UK 


\begin{abstract}
The settings approach appreciates that health determinants operate in settings of everyday life. Whilst subject to conceptual development, we argue that the approach lacks a clear and coherent theoretical framework to steer policy, practice and research.

Aims: To identify what theories and conceptual models have been used in relation to the implementation and evaluation of Healthy Universities.

Methods: A scoping literature review was undertaken between 2010-2013, identifying 26 papers that met inclusion criteria.

Findings: Seven theoretical perspectives or conceptual frameworks were identified: the Ottawa Charter; a socio-ecological approach (which implicitly drew on sociological theories concerning structure and agency); salutogenesis; systems thinking; whole system change; organisational development; and a framework proposed by Dooris. These were used to address interrelated questions on the nature of a setting, how health is created in a setting, why the settings approach is a useful means of promoting health, and how health promotion can be introduced into and embedded within a setting.

Conclusion: Although distinctive, the example of Healthy Universities drew on common theoretical perspectives that have infused the settings discourse more generally. This engagement with theory was at times well-developed and at other times a passing reference. The paper concludes by pointing to other theories that offer value to healthy settings practice and research and by arguing that theorisation has a key role to play in understanding the complexity of settings and guiding the planning, implementation and evaluation of programmes.
\end{abstract}

\title{
Key words
}

Health promotion; settings; healthy universities; health promoting universities; theory; conceptual framework; complexity; ecological; systems; salutogenesis.

\section{Introduction}

The rationale for the settings approach is based on the recognition that health is largely determined by people's environmental, economic, social, organisational and cultural circumstances. In addition to 
operating at a societal level, these influences operate in and through settings of everyday life, directly and indirectly influencing health. It follows that effective health promotion requires us to focus on the places in which people live their lives. The settings approach moves beyond the delivery of individuallyoriented lifestyle-focused health promotion in a setting, appreciating that the contexts in which people live their lives are themselves crucially important in determining health [1].

Although there is widespread recognition of the diverse health determinants operating in the settings of everyday life, there has been relatively little work focused on increasing understanding of how these determinants are influenced by social processes and mechanisms. Furthermore, whilst the settings approach has been subject to a degree of conceptual development, we would argue that it lacks a clear and coherent theoretical framework that could provide a strong rudder to steer policy, practice and research. That we refer to an approach implies that there is a shared perspective and understanding of a way of working; yet although there may be a purpose to create health, there may be less clarity about what is looked for that might constitute effectiveness. Cochrane reviews of evidence now argue that a prima facie criterion for assessing quality of intervention studies is an explicit link to theory [2], which can be defined as systematically organized knowledge applicable in different circumstances devised to analyse, predict or explain events or situations and causal connections between different variables. With regard to settings, theory can help to clarify how health is produced or inhibited and the relationships between context, structures and individual action. To the extent that theories have not been tested in relation to a setting, they may often more accurately be described as 'models' or 'conceptual frameworks' - and, indeed, there is ambiguity within the literature. For example, Antonovsky variously described salutogenesis as a model, an orientation and a springboard for the development of theory [3]. What theories, conceptual maps and models all do is structure our thinking and action about a problem. They provide a rationale to justify decisions for developing interconnected interventions and help identify which indicators should be monitored and measured during evaluation [4]. Settings are described and analysed drawing from multiple disciplines such as sociology, psychology, management and geography reflecting interest not only in the behaviour of individuals, but also in relation to structures, processes, policies and place $[5,6]$. Through focusing specifically on Healthy Universities ${ }^{1}$ as one example of the settings approach, this paper reviews the current place of theory and discusses the

1 While it can be argued that there are semantic differences between the terms 'health promoting settings' and 'healthy settings', they have often been used interchangeably. For the purposes of this article, the term 'Healthy Universities' is used throughout, even though the review and discussion draws on literature that has used the term 'Health Promoting Universities'. 
potential for strengthening theorisation as a tool for guiding future policy, practice and research. Universities are a relatively 'new' setting where both programmes and theorisation are still being developed. They provide therefore, an opportunity to explore specific settings theory and the potential for strengthening theorisation as a tool for guiding future policy, practice and research.

\section{Aims}

We built on earlier conceptual work in the field which had scoped the generic literature on the settings approach to health promotion $[1,7,8]$ by conducting a scoping review of the literature specifically related to the university as a healthy setting. In so doing, we sought to identify which theories and conceptual models have been used in relation to the implementation and evaluation of Healthy Universities and the central questions that they seek to illuminate..

\section{Methods}

A search of English language literature was conducted in 2010 and repeated in 2013. The search terms 'Healthy University/ies' and 'Health Promoting University/ies' were used in the following databases: CINAHL, ASSIA, Medline, Education Research Complete, EMBASE and ETHOS. Grey literature searches included Index to Theses and Google Scholar and websites relating to known national networks supporting Healthy Universities.

Inclusion criteria included:

- Full text available in English

- Written between 1994 (the year when the University of Lancaster established the first Healthy University initiative in the UK) to the present (2013)

- Refers to higher education or university (colleges or further education were excluded)

- Focuses on the planned improvement of health and wellbeing for the whole university community (references referring only to students or to staff were excluded).

References found were reviewed against the inclusion criteria by a member of the research team and checked by a second researcher. 


\section{Findings}

Of the 156 references found through the initial search, the majority did not focus on the whole university community - referring rather to targeted interventions or discrete studies addressing a specific health issue. 26 references [9-34] - relating to the UK, China, Germany, Hong Kong and the USA - conformed to the inclusion criteria. Of these, 15 were authored or co-authored by Dooris or Dooris et al [9-23] and a further seven cited Dooris or Dooris et al [24-30]. This reflects the relative youth of Healthy Universities as a movement and there was, not surprisingly, a high degree of congruence amongst the papers with regard to the theories and conceptual frameworks deployed.

Table I indicates the foci of the papers and provides a summary of the concepts and theories referred to. Reference ranged from a mention, a framework for reasoning to an exposition of a conceptual framework. Alongside a specific concern with the role of national frameworks and networks in supporting Healthy Universities, major considerations included the value of applying the settings approach to higher education and the effective establishment, implementation and integration of Healthy University initiatives. All but three papers referred to 'Health for All' principles and/or the Ottawa Charter, several using the latter as a conceptual framework to guide research and practice. Whilst the Ottawa Charter is itself rooted in an understanding of health as multi-faceted and created through the complex interplay between people and environments, half the papers went further by explicitly discussing an ecological or socio-ecological model of health and wellbeing. Although only eight papers discussed the need to shift towards a focus on positive health and/or adopt a salutogenic orientation, a number of others identified health as a holistic concept supported and maintained through the setting itself and acknowledged the importance of moving beyond the delivery of health promotion interventions in the setting. Of 19 papers that also made explicit reference to a whole system approach to change, 11 drew in more detail on systems thinking and 13 on organisational development theories, viewing these as key to embedding health and wellbeing within the university context. Finally, four recent papers by Dooris et al referred to Dooris' conceptual framework [1, 8], which suggests that the settings approach is characterised by an ecological model of health, a systems perspective and a whole system focus. 
Table I: Scoping review - questions, theories and conceptual frameworks referred to in the sources

\begin{tabular}{|c|c|c|c|c|c|c|c|c|}
\hline \multirow[t]{2}{*}{ Papers } & \multirow[t]{2}{*}{ Issues Addressed } & \multicolumn{7}{|c|}{ Concepts and Theories } \\
\hline & & 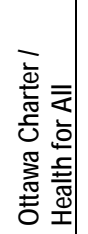 & 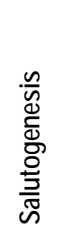 & 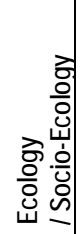 & 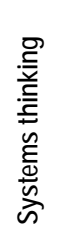 & 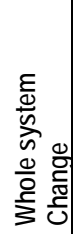 & 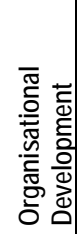 & 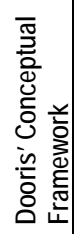 \\
\hline $\begin{array}{l}\text { 9. Cawood, Dooris, } \\
\text { Powell (2010) }\end{array}$ & $\begin{array}{l}\text { Why is higher education an important setting? } \\
\text { How has the HU 'movement' developed? }\end{array}$ & $\checkmark$ & & $\checkmark$ & & $\checkmark$ & & \\
\hline $\begin{array}{l}\text { 10. Doherty, Dooris } \\
\text { (2006) }\end{array}$ & $\begin{array}{l}\text { What characterises Healthy Colleges and HUs? } \\
\text { How have Healthy Colleges and HUs developed and } \\
\text { how should they develop in the future? }\end{array}$ & $\checkmark$ & & & & $\checkmark$ & & \\
\hline 11. Dooris (1999) & $\begin{array}{l}\text { How valuable is the } \mathrm{HU} \text { approach for promoting } \\
\text { holistic mental wellbeing and how can it be used? }\end{array}$ & $\checkmark$ & $\checkmark$ & $\checkmark$ & & $\checkmark$ & $\checkmark$ & \\
\hline 12. Dooris (2001) & $\begin{array}{l}\text { How can a holistic, comprehensive and integrative } \\
\text { HUs approach be established and embedded and } \\
\text { what are the challenges? }\end{array}$ & $\checkmark$ & $\checkmark$ & $\checkmark$ & $\checkmark$ & $\checkmark$ & $\checkmark$ & \\
\hline 13. Dooris (2001) & $\begin{array}{l}\text { How can a HU initiative be developed and } \\
\text { embedded and what are the challenges? }\end{array}$ & $\checkmark$ & & & & $\checkmark$ & $\checkmark$ & \\
\hline 14. Dooris (2002) & $\begin{array}{l}\text { How can a HU initiative be developed and } \\
\text { embedded and what are the challenges? }\end{array}$ & $\checkmark$ & & & & $\checkmark$ & & \\
\hline 15. Dooris (2010) & $\begin{array}{l}\text { Can a national HUs framework be established and } \\
\text { what would it look like? }\end{array}$ & $\checkmark$ & & & $\checkmark$ & $\checkmark$ & $\checkmark$ & \\
\hline $\begin{array}{l}\text { 16. Dooris, Cawood, } \\
\text { Doherty, Powell (2010) }\end{array}$ & $\begin{array}{l}\text { How can health be embedded within an organisation } \\
\text { where it is not core business - and what does a } \\
\text { model for HUs look like? } \\
\text { Can a national HUs framework be established and } \\
\text { what would it look like? }\end{array}$ & $\checkmark$ & & $\checkmark$ & $\checkmark$ & $\checkmark$ & $\checkmark$ & $\checkmark$ \\
\hline $\begin{array}{l}\text { 17. Dooris, Doherty } \\
\text { (2009) }\end{array}$ & $\begin{array}{l}\text { How can health be embedded into an organisation } \\
\text { where it is not core business? } \\
\text { What is the value of and potential for a national HUs } \\
\text { programme/framework and what would it look like? }\end{array}$ & $\checkmark$ & $\checkmark$ & $\checkmark$ & $\checkmark$ & $\checkmark$ & $\checkmark$ & $\checkmark$ \\
\hline $\begin{array}{l}\text { 18. Dooris, Doherty } \\
\text { (2010) }\end{array}$ & $\begin{array}{l}\text { What is the value of and potential for a national HUs } \\
\text { programme/framework and what would it look like? }\end{array}$ & $\checkmark$ & & $\checkmark$ & $\checkmark$ & $\checkmark$ & & $\checkmark$ \\
\hline $\begin{array}{l}\text { 19. Dooris, Doherty } \\
\text { (2010) }\end{array}$ & $\begin{array}{l}\text { What 'healthy universities' activity is taking place } \\
\text { within English universities and what are the key } \\
\text { challenges? }\end{array}$ & $\checkmark$ & & $\checkmark$ & $\checkmark$ & $\checkmark$ & $\checkmark$ & $\checkmark$ \\
\hline $\begin{array}{l}\text { 20. Dooris, Doherty, } \\
\text { Cawood, Powell (2012) }\end{array}$ & $\begin{array}{l}\text { Why is higher education an important setting? } \\
\text { How has the HU 'movement' developed? } \\
\text { How can the settings approach be applied to higher } \\
\text { education? } \\
\text { What are the future opportunities and challenges? }\end{array}$ & $\checkmark$ & & & $\checkmark$ & $\checkmark$ & $\checkmark$ & \\
\hline 21. Dooris, Martin (2002) & $\begin{array}{l}\text { What is the value of the HU approach? } \\
\text { How can a HU initiative be developed? }\end{array}$ & $\checkmark$ & & & & & & \\
\hline 22. Orme, Dooris (2010) & $\begin{array}{l}\text { How can HU create synergy between public health, } \\
\text { sustainable development and climate change? }\end{array}$ & $\checkmark$ & & $\checkmark$ & $\checkmark$ & $\checkmark$ & & \\
\hline $\begin{array}{l}\text { 23. Tsouros, Dowding, } \\
\text { Thompson, Dooris (Eds) } \\
\text { (1998) }\end{array}$ & $\begin{array}{l}\text { What is the value and potential of HUs and how has } \\
\text { the approach been developed? } \\
\text { What should a strategic framework for HUs look } \\
\text { like? }\end{array}$ & $\checkmark$ & $\checkmark$ & $\checkmark$ & $\checkmark$ & $\checkmark$ & $\checkmark$ & \\
\hline $\begin{array}{l}\text { 24. Davies, Newton } \\
\text { (2010) }\end{array}$ & $\begin{array}{l}\text { How can the University of Brighton be established as } \\
\text { a HU? }\end{array}$ & $\checkmark$ & $\checkmark$ & $\checkmark$ & $\checkmark$ & $\checkmark$ & $\checkmark$ & \\
\hline 25. Davies, Hall (2011) & $\begin{array}{l}\text { What progress has been made in developing the } \\
\text { University of Brighton be established as a } \mathrm{HU} \text { - and } \\
\text { what is the way forward? }\end{array}$ & $\checkmark$ & $\checkmark$ & $\checkmark$ & $\checkmark$ & $\checkmark$ & $\checkmark$ & \\
\hline $\begin{array}{l}\text { 26. Knight, La Placa } \\
\text { (2013) }\end{array}$ & $\begin{array}{l}\text { How can a HU initiative be developed and } \\
\text { implemented? }\end{array}$ & & & $\checkmark$ & & & $\checkmark$ & \\
\hline $\begin{array}{l}\text { 27. Stock, Milz, Meier } \\
\text { (2010) }\end{array}$ & $\begin{array}{l}\text { How effectively has the German national HUs } \\
\text { network functioned and how can it best support } \\
\text { future developments? }\end{array}$ & $\checkmark$ & & & & $\checkmark$ & $\checkmark$ & \\
\hline $\begin{array}{l}\text { 28. University College } \\
\text { Cork (2012) }\end{array}$ & How can a HU initiative be developed? & $\checkmark$ & $\checkmark$ & & & $\checkmark$ & $\checkmark$ & \\
\hline
\end{tabular}




\begin{tabular}{|c|c|c|c|c|c|c|c|}
\hline 29. Whitehead (2004) & How can nurses be involved with HUs? & $\checkmark$ & & & $\checkmark$ & & $\checkmark$ \\
\hline $\begin{array}{l}\text { 30. Xiangyang, Lan, } \\
\text { Xueping, Tao, Yuzhen, } \\
\text { Jagusztyn (2003) }\end{array}$ & $\begin{array}{l}\text { How can HUs be established in Beijing and what is } \\
\text { the value of this approach? }\end{array}$ & $\checkmark$ & & & & & \\
\hline $\begin{array}{l}\text { 31. Coffey, Coufopolouos } \\
\text { (2010) }\end{array}$ & $\begin{array}{l}\text { How can a needs assessment conducted as a } \\
\text { student health promotion project enhance the } \\
\text { curriculum and contribute to the strategic } \\
\text { development of a HU? }\end{array}$ & $\checkmark$ & & & & & $\checkmark$ \\
\hline $\begin{array}{l}\text { 32. Faculty of Public } \\
\text { Health Medicine (1995) }\end{array}$ & How can HUs be established? & $\checkmark$ & & & & & $\checkmark$ \\
\hline 33. Lee (2002) & How a HU initiative be developed? & & & & & $\checkmark$ & \\
\hline $\begin{array}{l}\text { 34. Zimmer, Hill, Sonnad } \\
\text { (2003) }\end{array}$ & $\begin{array}{l}\text { What is the scope of health promotion for the whole } \\
\text { higher education community and what are } \\
\text { appropriate quality standards? }\end{array}$ & & $\checkmark$ & $\checkmark$ & & & \\
\hline
\end{tabular}

\section{Discussion}

The scoping review suggests that the literature on Healthy Universities is located within the broader discourse on healthy settings and has a diverse and multi-disciplinary base informed by a mix of theories. Some of these theories are drawn on explicitly, providing an analysis or plan for intervention, although others - whilst not always 'named' - have an implicit influence. The Ottawa Charter is informed by both a salutogenic focus on positive health that may be created, produced and maintained in and through settings; and an understanding of health as multi-layered, multi-component and determined by a complex interaction of factors within and between people and their environments which constitutes a socio-ecological perspective and represents a shift of focus towards a holistic view. Although not specifically referred to, this focus on person-environment interaction also draws on sociological theory concerning the duality of structure and agency. The view of universities as complex contexts, acknowledging interconnectedness and synergy between different components, draws from systems theory; and the focus on a whole university approach and the use of multiple and interconnected interventions to embed health within the culture and ethos of settings draws on learning from organisation development.

Table II outlines these theories and summarises the ways in which they illuminate how health can be produced and enhanced in a setting. In exploring the key considerations highlighted above - the value of applying the settings approach to higher education; the effective establishment, implementation and integration of Healthy University initiatives; and the role of national frameworks and networks in supporting Healthy Universities - the literature addresses a number of inter-related questions: What is a setting? What is health and how is it created? Why is the settings approach an important and useful means of promoting health? How can health promotion be introduced into and embedded within a setting? These are used below to discuss how different theories are drawn on and utilised. 
Table II: How key theories illuminate healthy settings practice and research

\begin{tabular}{|c|c|c|c|c|}
\hline Theory & Seeks to explain: & Key features & How it illuminates setting & How creates health \\
\hline $\begin{array}{l}\text { Salutogenesis } \\
\text { (links with assets model) }\end{array}$ & $\begin{array}{l}\text {-The origins of health and how } \\
\text { positive health is produced. }\end{array}$ & $\begin{array}{l}\text { - Focus on resources for health - General } \\
\text { Resistance Resources (e.g. money, } \\
\text { knowledge, self-esteem, social support, } \\
\text { cultural capital) contributing to Sense of } \\
\text { Coherence (comprehensibility, } \\
\text { manageability, meaningfulness). }\end{array}$ & $\begin{array}{l}\text {-Shifts focus from deficit model. } \\
\text {-Strengthens sense of place and sense of self. } \\
\text { - Active participation in valued decision making. } \\
\text {-A humanistic approach. }\end{array}$ & $\begin{array}{l}\text { - Suggests health is created in setting when } \\
\text { people have a shared sense of meaning and } \\
\text { a shared purpose. } \\
\text { - People understand what they have to do } \\
\text { and they have the resources to do it. }\end{array}$ \\
\hline Social-ecology & $\begin{array}{l}\text {-The forces shaping the } \\
\text { development of human beings in } \\
\text { the environments in which they } \\
\text { live and the impact of human } \\
\text { activity on that environment. }\end{array}$ & $\begin{array}{l}\text { - Focus on importance of context. } \\
\text { - Recognises complexity. Interactions and } \\
\text { interrelations between people and their } \\
\text { environments. }\end{array}$ & $\begin{array}{l}\text { - Shifts focus from deficit model. } \\
\text { - Health is product of interdependence between } \\
\text { individuals and subsystems of the ecosystem } \\
\text { (includes family, community, culture, physical and } \\
\text { social environment). } \\
\text { - Health is a pattern of relations and requires } \\
\text { interventions on multiple levels. }\end{array}$ & $\begin{array}{l}\text { - Creation of health relates to wider } \\
\text { contexts. } \\
\text { - Health is product of interdependence } \\
\text { between people and their environments, } \\
\text { including natural, physical and social. } \\
\text { - There is a range of relationships and power } \\
\text { is a critical factor. }\end{array}$ \\
\hline $\begin{array}{l}\text { Organisation } \\
\text { development }\end{array}$ & $\begin{array}{l}\text { - How health can make an } \\
\text { organisation perform better, } \\
\text { how a commitment to and } \\
\text { investment in health can be } \\
\text { embedded in the culture, } \\
\text { structures, mechanisms and } \\
\text { routine life of an organisation. }\end{array}$ & $\begin{array}{l}\text { - Aim is to ensure that health becomes } \\
\text { part of the organisation. } \\
\text { - Change must be achieved by the } \\
\text { organisation itself. }\end{array}$ & $\begin{array}{l}\text {-Organisations are seen as social settings that can } \\
\text { either support or harm the health of their members } \\
\text { through working conditions, patterns of behaviour } \\
\text { and values and standards. }\end{array}$ & $\begin{array}{l}\text { - Health is created or limited/harmed by how } \\
\text { organisations function. }\end{array}$ \\
\hline Systems theory & $\begin{array}{l}\text { - How change occurs in complex } \\
\text { systems such as human social } \\
\text { systems. }\end{array}$ & $\begin{array}{l}\text { - Takes account of whole system to bring } \\
\text { about change in particular contexts. } \\
\text { - Understands systems as more than } \\
\text { mechanistic structures - stresses } \\
\text { importance of connections, patterns, } \\
\text { relationships and meaning. } \\
\text { - Increasingly informed by complexity } \\
\text { theory. }\end{array}$ & $\begin{array}{l}\text {-Acknowledges that social systems are non-linear, } \\
\text { self-organising networks, with varying/competing } \\
\text { interests. } \\
\text { - Appreciates that systems have to adapt to other } \\
\text { agents and the changing environment, which is } \\
\text { affected by actions of agents and feedback loops. }\end{array}$ & $\begin{array}{l}\text { - Must see setting as more than organisation } \\
\text { and as a whole system, with focus on social } \\
\text { and political processes and patterns, } \\
\text { relationships and meaning. } \\
\text { - Healthy structures and processes are pre- } \\
\text { requisites for health. }\end{array}$ \\
\hline Sociological theories & $\begin{array}{l}\text { - The complex interaction } \\
\text { between structure and agency. }\end{array}$ & $\begin{array}{l}\text {-Questions whether human behaviour is a } \\
\text { consequence of people making free } \\
\text { choice or an outcome of the world } \\
\text { around them. } \\
\text { - Structures are laden with differences in } \\
\text { power, thus empower individuals } \\
\text { differently. }\end{array}$ & $\begin{array}{l}\text {-Emphasises the interplay of structural and } \\
\text { behavioural factors, and dynamic exchange between } \\
\text { people and their environments. } \\
\text {-Highlights the role of power relations. }\end{array}$ & $\begin{array}{l}\text { - Production of health depends on interplay } \\
\text { of structural factors and human agency, } \\
\text { and dynamic exchange between people and } \\
\text { their environments. } \\
\text { - Links with empowerment, enablement and } \\
\text { healthy public policy. }\end{array}$ \\
\hline
\end{tabular}




\section{What does it mean to consider the university as a setting?}

Reflecting Wenzel's definition of settings as "spatial, temporal and cultural domains of face-to-face interaction in everyday life" [35] and Green, Poland and Rootman's observation that settings are both the medium and product of social interaction [5], the university setting is widely viewed as a context within which particular people (students, staff) live aspects of their daily lives and with which others (families, external services, wider community) interact. Whilst having commonalities with many other settings, this context is distinctive and informed by sector-led thinking about the current and future role of higher education $[20,23]$.

Drawing on settings-focused literature by Baríc [36] and Grossman and Scala [37], universities have also been conceptualised as social systems, with inputs, processes and outputs [8, 12]. As systems, they are understood to be made up of multiple interconnected parts - which can be considered in terms of components; micro-environments; sub-populations or stakeholder groups; and health issues and their determinants $[5,15]$. Systems theory has proved to be a powerful influence in the field of healthy settings, particularly in terms of how health can be embedded within a context oriented to non-health goals.

\section{What is health and how is it created in the university?}

Informed by the Ottawa Charter, the Healthy Universities approach views health as a multi-dimensional (physical, mental, emotional, spiritual, social) resource for living. Echoing Kickbusch [38], the focus for the Healthy University is not only on identifying needs and encouraging behaviour change and disease prevention, but also on fostering health assets and strengthening resources for health, wellbeing and human flourishing. In understanding the ways in which health is created or inhibited by a setting, the Healthy Universities discourse draws from Antonovsky's concept of salutogenesis [3], which he argues provides the theoretical answer to the question 'what explains movement toward the health pole of the health-ease/dis-ease continuum?' This theory focuses on the development of 'general resistance resources' - biological, material and psychosocial factors that make it easier for people to perceive their lives as comprehensible, manageable and meaningful - thereby promoting a strong 'sense of coherence'. Informed by the theoretical orientation of salutogenesis, the settings approach asks the questions: 'what can be done to nurture the health potentials inherent in this particular context and so promote wellbeing and positive health?' and 'what will strengthen the resources available to people and empower them to increase control over the determinants of health and to thrive?' This informs a view 
about universities providing a supportive context for students undergoing a life transition - exploring, experimenting and developing independence and lifeskills.

Many of the Healthy Universities papers mirror wider healthy settings literature in understanding health to be created and lived in the inter-relationships between different people and between people and the circumstances in which they live. This understanding draws strongly on social ecology theory [39], which originates from the discipline of human ecology [40]. The key assumptions are that health and wellbeing include multiple dimensions and are influenced by the dynamic interplay of diverse facets of the physical and social environments and a variety of personal attributes [39]. More recently, the focus has broadened to explore the relevance to settings of wider ecological thinking [41], highlighting the essential interconnections between the health of people and the health of the planet [22].

Closely linked to this focus on the interplay between a person and their environment is an attempt to understand whether health is primarily created by human behaviour and is the consequence of people making free choices (agency) or produced as an outcome of the world around them (structure) [42] . As in any setting, it is important to take account of power relations and inequalities within the university context, appreciating that different 'stakeholders' have different degrees of access to and control over the determinants of their health and wellbeing [43]. This interaction between structure and agency is brought into focus when considering the extent to which students have the power and agency to make behavioural choices and how these may be constrained by political and economic determinants such as university fee structures.

\section{Why is the settings approach an important and useful means of promoting health in and through the University?}

The Healthy Universities literature identifies key facets of the higher education context that can be harnessed to promote and maintain health, for example through learning and development or education for global citizenship. This reflects a wider appreciation that health determinants operate at multiple levels and that settings represent an important tier of influence and an important focus for health-related investment and intervention. Similarly influenced by social ecology theory [39] it is recognised that these underlying factors and conditions are inter-related and can be most effectively tackled not by 'single thread' interventions, but through a comprehensive and integrated whole system approach undertaken within the contexts of everyday life $[1,8]$. 
Drawing on the work of Baríc [36], it has been argued extensively that a whole system Health Universities approach requires a three-fold commitment to: creating working and living environments that support and strengthen health potentials; integrating an understanding of and commitment to health within the ethos, culture, routine life and mainstream business of the setting (in the case of universities, learning, teaching, research and knowledge exchange); and engaging with and promoting the health and wellbeing of the wider community.

\section{How can health promotion be introduced into and embedded within a setting?}

The university setting can be understood as a social system. Systems theory is concerned with looking at the system in its entirety, the interrelationships between its parts and their relationships to the whole [44]. It assumes that they are both complex and dynamic and either in equilibrium or change, with elements affected through feedback loops. When applied to health, the theory helps to illustrate that healthy structures (e.g. a strategic plan and management commitment) are a pre-condition for healthy processes (e.g. effective communication and participatory decision-making) and that both are preconditions for healthy outputs and outcomes and are therefore determinants of health. Using systems thinking changes the perception of where health is produced and inhibited in a setting and can help to clarify how to initiate and implement whole system change.

Because one of the aims of the healthy settings approach is to move health into the contexts of everyday life, it is important to understand how organisations such as universities work, in order to ensure that health can become truly embedded within this and other settings that do not have health as their raîson d'être $(37,45)$. The key challenge is thus to find ways to align health with the organisation's core business and initiate and/or manage change. Whilst acknowledging the many challenges involved, Grossman and Scala [37] suggest that organisational development theories and methods provide the overall means of identifying how health can make an organisation perform better, and how a commitment to and investment in health can be embedded in the culture, structures, mechanisms and routine life of the organisation.

\section{Conclusion}

The WHO glossary [46] defined a 'setting for health' as the social context in which people interact to affect wellbeing and create or solve problems relating to health. Most settings are in reality oriented to 
goals other than health and have pre-existing structures, policies, characteristics and institutional values. A settings approach will therefore involve understanding not only how contexts, facilitie, services and programmes impact on wellbeing but also how health can be effectively integrated within the culture, structures, routine life and core business of settings - and how these interface with the resources, motivations and actions of the people within them.

Notwithstanding the distinctiveness of higher education as a context, this scoping review of Healthy Universities has identified a range of theoretical influences that accord with the emphases found within generic literature on healthy settings - specifically salutogenesis, socio-ecology, sociological perspectives relating to structure and agency, systems thinking and organisation development. We have suggested that conscious engagement with these theories can help to elucidate some central interrelated questions concerning the nature of the university as a setting, the concept of health, and the effective introduction and integration of health promotion. Furthermore, we would argue that such engagement can help to ensure that the development, implementation and evaluation of the settings approach is theory-driven, and enhance its overall design and effectiveness.

It will be important to appreciate that there are other perspectives not yet prominent in the discourse on Healthy Universities that may help further illuminate the effective application of the settings approach to higher education and other contexts. For example, it has been suggested that healthy settings practice and research could usefully engage with both complexity theory [47] and critical realism [1]. With its focus on the complex and adaptive nature of systems, the former emphasises the emergent, organic and non-linear character of innovation and adaptation, prioritises co-evolution and distributed rather than centralised power and control, and highlights new ways of understanding organizational and social development and change. It thus helps to move beyond the somewhat instrumental systems-based conceptualisation of settings proposed by Baríc [36]. Critical realism focuses on the interconnections between structure and agency and draws attention to context and social relationships as generative mechanisms that influence outcomes. It can therefore help us understand better how and why particular settings programmes work or fail in particular circumstances and at particular times. It appreciates that social structures can both enable and constrain individual action and that, as agents, people are also able to influence and transform these structures. Distinguishing between the real, the actual and the empirical, it views causality within complex social systems as multi-faceted. A key value for enhancing healthy settings practice and research lies in its appreciation that context is integral to an intervention or programme, not something to be 'controlled' 
for' $^{\prime}[48,49]-$ and that outcomes are dependent on the activation of generative mechanisms within particular contexts. When applied to evaluative research, critical realist theory can thus help us understand better how and why particular settings programmes work or fail in particular circumstances and at particular times. Moreover, Connelly [50] argues that critical realism is particularly attractive to health promotion because it similarly rejects ethical relativism and asserts values such as equality, justice and freedom.

Engagement with guiding values is particularly pertinent within the context of healthy settings programmes, many of which are focused on either geographic contexts which prioritise concepts such as citizenship and democratic governance (e.g. cities, communities) or organisational contexts which espouse the importance of public service provision (e.g. universities, schools, health care, prisons). Alongside critical realism, a more grounded perspective is offered by Public Value Theory [51], which highlights principles such as equity, accessibility and devolution of power and authority, and points to how the goals of the organization are articulated and their alignment with health.

The settings approach was born in the Ottawa Charter which claimed that health is not created outside of contexts but within the settings of people's everyday life. Both socio-ecological theory and the ideas of salutogenesis therefore inform the approach - and equally, the conceptual frameworks of systems theory and ideas of organisational development can help to inform the planning and implementation of settings initiatives, offering diverse and synergistic perspectives. Theorization provides both a lens and a framework which can help ensure that intervention and programme design and delivery are effective. Whilst the complexity of both 'health' and 'settings' necessitates that we draw on multiple theories from multiple disciplines, rather than one overarching theory, the absence of such theorizing risks settingsbased health promotion being understood and practised as the mere delivery of behaviour change interventions within particular contexts. This paper has argued that the settings approach offers a much richer and more powerful means of promoting health and wellbeing than this - but that its effective implementation is dependent on asking and being able to answer certain key theory-driven questions. Looking ahead, the key challenges, for researchers and practitioners alike, are to engage with and be explicit about which theories they are using; to assess critically and reflectively how they are using these theories and how healthy settings implementation can avoid the danger of instrumentality by taking various theoretical traditions more seriously in their own right; and to strengthen theory-oriented research within and across different settings.

\section{Conflict of interest}


The authors declare that there is no conflict of interest.

\section{Funding}

This research formed part of a PhD, supported by a scholarship funded by London South Bank University.

\section{References}

1. Dooris M, Poland B, Kolbe L, de Leeuw E, McCall D, Wharf-Higgins J. Healthy settings: building evidence for the effectiveness of whole system health promotion - challenges and future directions. In: McQueen D, Jones C (eds). Global perspectives on health promotion effectiveness. New York: Springer Science and Business Media, 2007. p. 327-52.

2. Armstrong R, Waters E, Jackson N, Oliver S, Popay J, Shepherd J, Petticrew M, Anderson L, Bailie R, Brunton G, Hawe P, Kristjansson E, Naccarella L, Norris S, Pienaar E, Roberts H, Rogers W, Sowden A, Thomas H. Guidelines for systematic reviews of health promotion and public health interventions. Version 2. Melbourne: Melbourne University, Australia, 2007.

3. Antonovsky A. The salutogenic model as a theory to guide health promotion. Health Promot Int 1996; 11: 11-18.

4. Bauer G, Davies JK, Pelikan J, Noack H, Broesskamp U, Hill C. Advancing a theoretical model for public health and health promotion indicator development. Eur J Public Health 2003; 13: 107-113.

5. Green, L., Poland, B. and Rootman, I. The settings approach to health promotion. In. Poland B, Green L, Rootman I (eds). Settings for health promotion: linking theory and practice. London: Sage, 2000, pp. 1-43.

6. Kokko, S., Green, L., Kannas, L. A review of settings-based health promotion with applications to sports clubs. Health Promot Int 2013;29:494-509.

7. Dooris M. Joining up settings for health: a valuable investment for strategic partnerships? Crit Public Health 2004; 14: 37-49.

8. Dooris M. Healthy settings: challenges to generating evidence of effectiveness. Health Promot Int 2006; 21: 55-65.

9. Cawood J, Dooris M, Powell S. Healthy universities: shaping the future. Perspectives in Public Health. 2010; 130(6): 259 - 60.

10. Doherty S, Dooris M. The healthy settings approach: The growing interest within colleges and universities. Education and Health. 2006; 24(3):42 - 3.

11. Dooris $\mathrm{M}$. The health promoting university as a framework for promoting positive mental well-being -a discourse on theory and practice. International Journal of Mental Health Promotion 1999; 1(4): 34-44. 
12. Dooris M. The health promoting university: A critical exploration of theory and practice. Health Education. $2001 ; 101: 51-60$.

13. Dooris M. Health Promoting Universities: policy and practice - a UK perspective. Community-Campus Partnerships for Health 5th Annual Conference, San Antonio, TX, May 5-8, 2001. Available at: http://depts.washington.edu/ccph/pdf_files/p-dooris.pdf - accessed 11 November 2013.

14. Dooris M. The health promoting university: Opportunities, challenges and future developments. Promotion \& Education. 2002; 9(Supplement): 20-24.

15. Dooris M. Towards a National Healthy University Framework for England. Preston: University of Central Lancashire; London: Royal Society for Public Health, 2010.

16. Dooris M, Cawood J, Doherty S, Powell S. Healthy Universities: Concept, model and framework for applying the healthy settings approach within higher education in England. Preston: University of Central Lancashire, London: Royal Society for Public Health, 2010.

17. Dooris M, Doherty S. National research and development project on Healthy Universities: Final report. Preston: University of Central Lancashire, London; London: Higher Education Academy, 2009.

18. Dooris M, Doherty S. Healthy universities - time for action: A qualitative research study exploring the potential of a national programme. Health Promot Int, 2010; 25(1): 94-106.

19. Dooris M, Doherty S. Healthy universities: current activity and future directions - findings and reflections from a national-level qualitative research study. Global Health Promotion, 2010; 17(3): 6-16.

20. Dooris M, Doherty M, Cawood J, Powell S. The healthy universities approach: adding value to the higher education sector. In A Scriven, M Hodgins (eds). Health promotion settings: principles and practice. London: Sage, 2012, pp. 153-169.

21. Dooris $\mathrm{M}$, Martin E. The health promoting university - from idea to implementation. Promotion \& Education, 2002; Suppl 1: 16-19.

22. Orme J, Dooris M. Integrating health and sustainability: The higher education sector as a timely catalyst. Health Education Research. 2010; 25(3): 425-37.

23. Tsouros A, Dowding G, Thompson J, Dooris M (eds). Health promoting universities: Concept, experience and framework for action. Copenhagen: WHO Regional Office for Europe, 1998. Available at: http://www.euro.who.int/_data/assets/pdf_file/0012/101640/E60163.pdf - accessed 11 November 2013.

24. Davies JK, Newton J. Developing the University of Brighton as a health promoting university: An interim review. Brighton: University of Brighton, 2010.

25. Davies JK, Hall C. Establishing the University of Brighton as a health promoting university: A pilot project final report. Brighton: University of Brighton, 2011

26. Knight A, La Placa V. Healthy Universities: Taking the University of Greenwich healthy universities initiative forward. International Journal of Health Promotion and Education, 2013; 51(1): 41 - 9. 
27. Stock C, Milz S, Meier S. Network evaluation: Principles, structures and outcomes of the German working group of Health Promoting Universities. Global Health Promotion. 2010; 17(1): 25-32.

28. University College Cork. 'UCC Health Matters Action Plan'. UCC 's journey to becoming an accredited health promoting university by 2014. Cork: University College Cork, 2012.

29. Whitehead D. The health promoting university: The role and function of nursing. Nurse Education Today, $2004 ; 24(6): 466-72$.

30. Xiangyang T, Lan Z, Xueping M, Tao Z, Yuzhen S, Jagusztyn M. Beijing health promoting universities: Practice and evaluation. Health Promotion International. 2003; 18(2): 107-13.

31. Coffey M, Coufopoulos A. Creating a 'health promoting curriculum' to inform the development of a health promoting university: a case study. International Journal of Health Promotion \& Education. 2010; 48(1): 48.

32. Faculty of Public Health Medicine. Health for All by the Year 2000 News, 1995; 31.

33. Lee S. Health promoting university initiative in Hong Kong. Promotion \& Education, 2002; Suppl 1: 15.

34. Zimmer C, Hill M, Sonnad S. A scope of practice survey leading to the development of standards of practice for health promotion in higher education. Journal of American College Health, 2003; 51(6): 247 54.

35. Wenzel E. A comment on settings in health promotion. Internet Journal of Health Promotion, 1997. Available athttp://ldb.org/setting.htm - accessed 14 August 2014.

36. Baríc L. The settings approach - implications for policy and strategy. J Inst Health Educ 1993; 31: 17-24.

37. Grossman R, Scala K. Health promotion and organisational development: developing settings for health. Copenhagen: WHO Regional Office for Europe, 1993.

38. Kickbusch I. Tribute to Aaron Antonovsky - 'what creates health'? Health Promot Int 1996; 11: 5-6.

39. Stokols D. Establishing and maintaining healthy environments: toward a social ecology of health promotion. Amer Psych 1992; 47: 6 - 22.

40. Bronfenbrenner U. The ecology of human development. Experiments by nature and design. Cambridge MA: Harvard University Press.

41. Rayner, G., Lang, T., 2012. Ecological Public Health: Reshaping the Conditions for Good Health. Routledge, Abingdon.

42. Abel T, Frohlich KL (2012) Capitals and capabilities: linking structure and agency to reduce health inequalities. Social Science and Medicine; 74 (2): 236-44

43. Poland B, Krupa G and McCall D. Settings for health promotion: an analytic framework to guide intervention design and implementation. Health Promot Pract 2010; 10: 505-16.

44. Checkland P. Systems thinking, systems practice. Chichester: Wiley; 1999. 
45. Kickbusch I. The contribution of the World Health Organization to a new public health and health promotion. Am J Public Health 2003; 93: 383-8.

46. World Health Organization. Health promotion glossary. WHO/HPR/HEP/98.1. Geneva, WHO, 1998.

47. Zimmerman B, Lindberg C, Plsek P Edgeware: Insights from complexity science for health care leaders, 2nd Ed. Irving, Texas: VHA Inc, 2001.

48. Poland B, K Frohlich, M Cargo (2008) Context as a fundamental dimension of health promotion program evaluation. In Potvin, L. McQueen, D. (eds). Health Promotion Evaluation Practice in the Americas: Values and Research. New York, NY: Springer, pp. 299-317.

49. Shareck, Frohlich, K. Poland, B. Reducing social inequities in health through settings-related interventions - a conceptual framework. Global Health Promotion 2013; 20(2): 39-52.

50. Connelly J. Critical realism and health promotion: Effective practice needs an effective theory. Health Education Research 2000; 16: 115-120.

51. Coats D, Passmore, E. Public Value: The Next Steps in Public Service Reform. London, Work Foundation, 2008. 